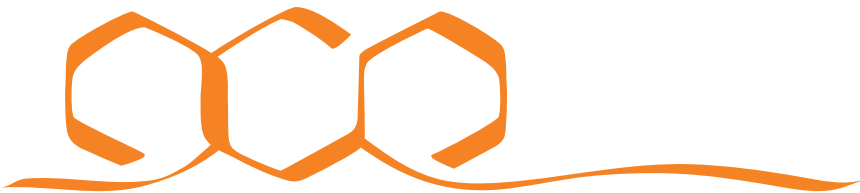 \\ COMMUNICATIONS CHEMISTRY
}

ARTICLE

https://doi.org/10.1038/s42004-019-0211-7 OPEN

\section{Auxiliary-assisted chemical ubiquitylation of NEMO and linear extension by HOIP}

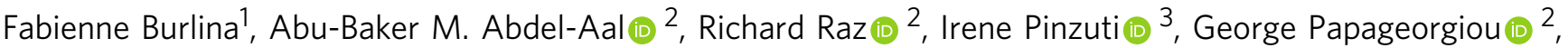 \\ Jiejin $\mathrm{Li}^{2}$, Robin Antrobus (10 ${ }^{4}$, Stephen R. Martin², Simone Kunzelmann (1) ${ }^{2}$, Benjamin Stieglitz $\mathbb{D}^{3} \&$ \\ John Offer (10) ${ }^{2}$
}

The ubiquitylation of NF- $\mathrm{kB}$ essential modulator (NEMO) is part of the intracellular immune signalling pathway. Monoubiquitylated NEMO is required for exploring the mechanism of NEMO linear ubiquitylation by LUBAC (linear ubiquitin chain assembly complex), but is not accessible by biological techniques. Here we perform the chemical ubiquitylation of NEMO using a ligation auxiliary, which only requires a two-step synthesis, and is easily installed onto the lysine side-chain. Chemical ligation occurs directly on the lysine $\varepsilon$ amine and remains efficient below $\mathrm{pH}$ 7. We show that ubiquitylated NEMO has similar affinity to linear diubiquitin chains as unmodified NEMO. The proximal ubiquitin of chemically synthesised $\mathrm{NEMO}_{\text {Cozi- }} \mathrm{Ub}$ is accepted as a substrate for linear extension by the (RING-Between-RING) RBR domain of HOIL-1-interacting protein (HOIP) alone. Our results indicate that NEMO linear ubiquitylation consists of two-steps, an initial priming event and a separate extension step requiring different LUBAC components.

\footnotetext{
${ }^{1}$ Sorbonne Université, École normale supérieure, PSL University, CNRS, Laboratoire des biomolécules, LBM, 75005 Paris, France. ${ }^{2}$ The Francis Crick Institute, 1 Midland Road, London NW1 1AT, UK. ${ }^{3}$ Department of Biochemistry, School of Biological and Chemical Sciences, Queen Mary University of London, Mile End Road, London E1 4NS, UK. ${ }^{4}$ Cambridge Institute for Medical Research, Cambridge Biomedical Campus, Wellcome Trust/MRC Building, Hills Road, Cambridge CB2 OXY, UK. Correspondence and requests for materials should be addressed to B.S. (email: b.stieglitz@qmul.ac.uk) or to J.O. (email: john.offer@crick.ac.uk)
} 
ntracellular immune signalling is largely mediated by posttranslational modification of proteins with ubiquitin (Ub) chains ${ }^{1}$. In particular, linear (or M1-linked) Ub chains promote activation of the NF- $\kappa \mathrm{B}$ (nuclear factor 'kappa-light-chainenhancer' of activated B-cells) pathway, a key event in mounting an inflammatory response to bacterial and viral infections ${ }^{2}$. NF$\kappa \mathrm{B}$ essential modulator (NEMO) is the regulatory subunit of IKK (inhibitor of nuclear factor kappa-B kinase), a kinase complex, which tightly regulates NF- $\mathrm{kB}$. Linear ubiquitylation of NEMO plays an essential role by promoting activation of IKK. NEMO is a dimeric $48 \mathrm{KDa}$ protein, containing many linear ubiquitylation sites, mostly in the CoZi (coiled-coil and leucine zipper) domain ${ }^{3}$. The CoZi domain is also the site that binds linear Ub chains with high specificity, required for the regulatory function of NEMO.

The linear ubiquitin chain assembly complex (LUBAC), is the only known ligase complex to synthesise linear ubiquitin. LUBAC is a hetero complex consisting of the three proteins HOIP (HOIL1-interacting protein), HOIL-1 (Heme-oxidized IRP2 ubiquitin ligase 1) and SHARPIN (Shank-associated RH domaininteracting protein) (Fig. 1). HOIP and HOIL-1 display linear $\mathrm{Ub}$ chain synthesis activity via their RING-Between-RING (RBR) domains ${ }^{4}$. HOIP is the major catalytic core of LUBAC and essential for linear ubiquitin chain synthesis ${ }^{5-7}$. The isolated Cterminal RBR domain of HOIP can synthesise free, unanchored Ub chains, whereas HOIL-1 displays only low basal chain assembly activity ${ }^{6}$. However, HOIL-1 is required for releasing autoinhibition of HOIP and might be required for ab initio ubiquitylation of $\mathrm{NEMO}^{8}$. Similar to HOIL-1, SHARPIN is also able to release autoinhibition, but does not display ubiquitylation activity. It has been proposed that HOIL-1 directs HOIP catalytic activity so that the initial donor $\mathrm{Ub}$ is transferred onto $\mathrm{NEMO}^{8}$. The molecular determinants for subsequent rounds of linear Ub chain elongation have not been established. So far it remains elusive if this reaction requires the entire LUBAC complex or if the HOIP catalytic core is sufficient for linear ubiquitylation of $\mathrm{Ub}$ primed NEMO. In order to investigate LUBAC mediated ubiquitylation of NEMO we wished to reconstitute the cascade for linear ubiquitylation including monoubiquitylated $\mathrm{NEMO}_{\mathrm{CoZi}}$ $\left(\mathrm{NEMO}_{\mathrm{CoZi}}-\mathrm{Ub}\right)$ as a substrate. While the reconstitution of the ubiquitylation cascade for free unanchored $\mathrm{Ub}$ chains is established by using purified proteins from bacterial expression systems, the investigation of linear chain synthesis in context of a substrate protein such as NEMO was not previously conceivable because monoubiquitylated NEMO was not obtainable from current biological expression systems.

Chemical protein synthesis enables a virtually limitless choice of functionalities at defined positions and has evolved into a powerful technique for exploring the biological role of posttranslational modifications (PTMs), notably ubiquitylation ${ }^{9-11}$. There are several approaches used to form the native isopeptide attachment. The most widely used methods are extensions of native chemical ligation (NCL); including the use of $\delta$-thiolysine (in both synthetic ${ }^{12}$ and recombinant proteins ${ }^{13}$ ) and $\gamma$ thiolysine ${ }^{14}$, or the use of a ligation auxiliary, removed after ligation by photolysis ${ }^{15,16}$, acidolysis ${ }^{17}$, or reduction ${ }^{18}$. Auxiliaries are notorious for being practically limited to only the most sterically unhindered ligation junctions. From steric considerations, formation of the isopeptide bond would appear to be ideal for the auxiliary approach but in practice ligation has usually been performed at one remove from the isopeptide bond between the two glycines of ubiquitin. This is probably because of the high pka of the lysine side-chain and therefore ubiquitylation is largely prevented at neutral $\mathrm{pH}$ as the lysine side-chain amine is protected by protonation. The 1-(2,4-dimethoxyphenyl)-2-mercaptoethyl auxiliary ${ }^{17}$ has been the most widely used auxiliary for ubiquitylation and many impressive targets have been successfully prepared with it ${ }^{19-22}$. However, as also for the mercaptolysine approach, it requires multi-step synthesis to prepare the protected building blocks and several equivalents are required for peptide synthesis. Some alternative approaches have overcome these difficulties by avoiding the use of an auxiliary or mercaptolysine ${ }^{23,24}$.

For our synthesis of $\mathrm{NEMO}_{\mathrm{CoZi}^{-}} \mathrm{Ub}$, we wanted an easily synthesised auxiliary that could be installed directly onto the lysine $\varepsilon$-amine post-synthesis (Fig. 2). In contrast the current auxiliary approaches for ubiquitylation couple a fully-protected auxiliary derivatized amino acid building block. The 2,3,4-trimethoxymercaptobenzyl (Tmb) auxiliary has been widely applied to the synthesis of proteins and conjugates ${ }^{25-29}$. Unlike other comparable auxiliaries such as 1-(2,4-dimethoxyphenyl)-2-mercaptoethyl or thiol-derivatized lysine, it has no chiral centre (and therefore no accompanying HPLC peak-splitting or broadening) and can be used in the presence of unprotected cysteines ${ }^{28}$. Tmb, like other auxiliaries, is generally added as a fully-protected building block ${ }^{19}$ (auxiliary attached to a protected amino acid). This is because aldehydes generally undergo inefficient reductive

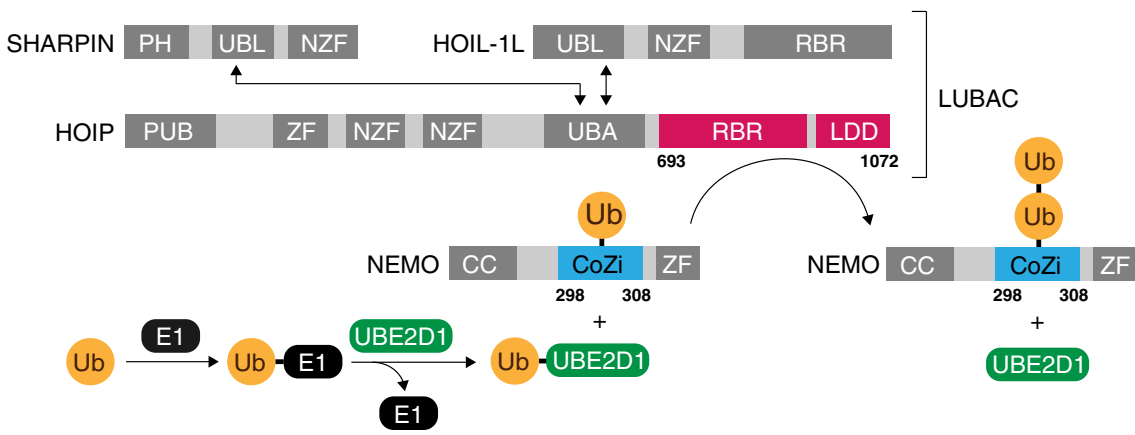

Fig. 1 Schematic overview of the ubiquitylation pathway of NEMO. Ubiquitin is activated by an E1 enzyme (black) and passed onto the E2 enzyme UBE2D1 (green) in a transthiolation reaction. LUBAC, which consists of the three proteins HOIP, HOIL-1L and SHARPIN catalyses the formation of a peptide bond between the N-terminus of a ubiquitin molecule which has been conjugated to NEMO and the C-terminus of the activated ubiquitin provided by UBE2D1. Interaction between the UBL (ubiquitin like) domains of HOIL-1L and SHARPIN with the UBA (ubiquitin associated) domain of HOIP is required for full activity under in vivo condition. The formation of di-ubiquitin conjugated to lysine 303 was reconstituted under in vitro conditions using the minimal catalytic core of LUBAC, consisting of the RBR (RING in between RING) and LDD (linear chain determining) domain of HOIP (residues 693-1072, shown red) and the fully synthetic CoZi domain of NEMO (residues 298-308, shown in blue) ligated to ubiquitin (orange). The domains of HOIP and the two proteins HOIL-1L and SHARPIN, which are not present in the reconstitution system are shaded in grey (PH peckstrin homology, NZF Npl4 zinc finger, PUB PNGase/UBA/UBX, ZF zinc finger) 


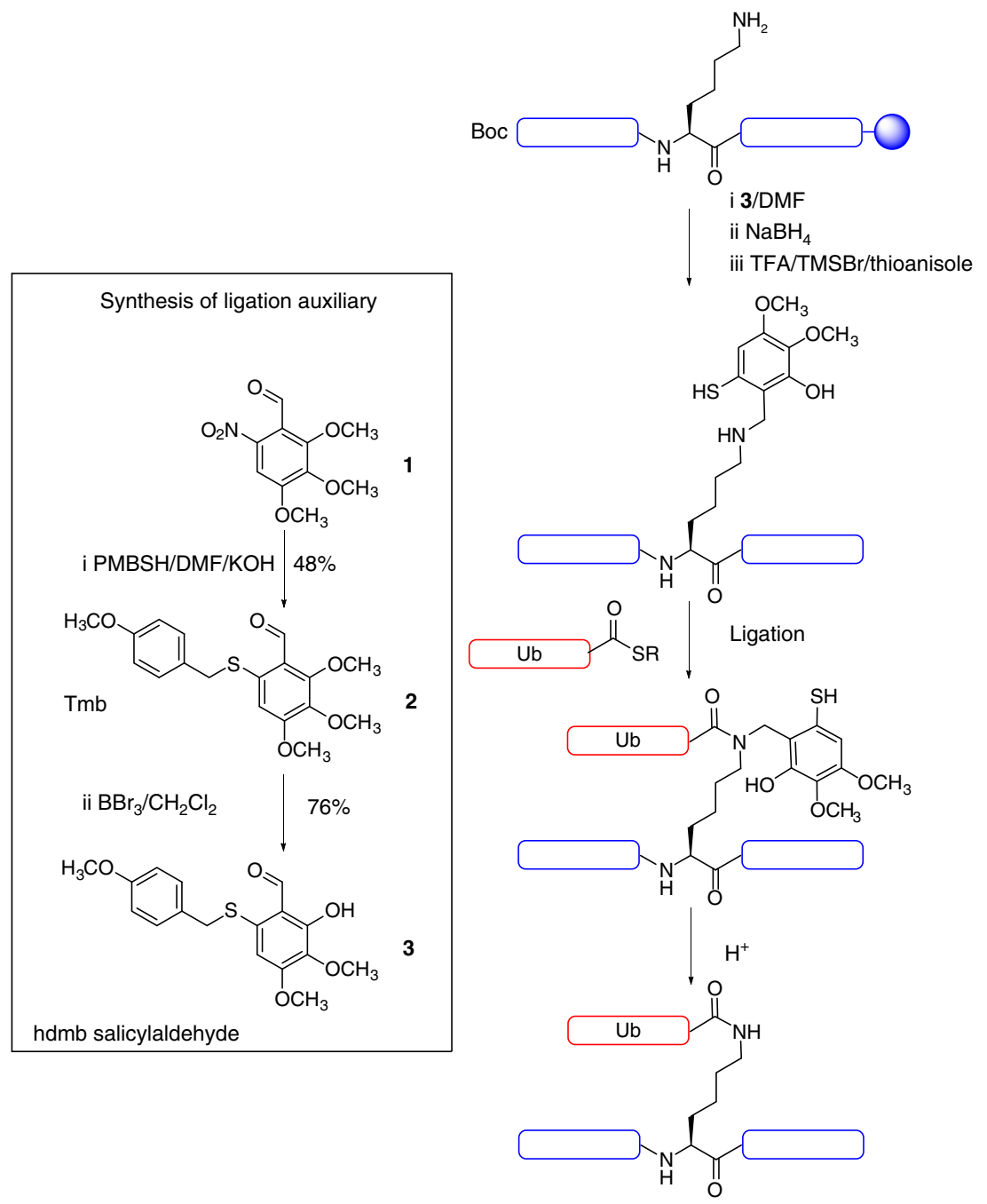

Fig. 2 General strategy of hdmb auxiliary-assisted ubiquitylation. Synthesis of the hdmb salicylaldehyde ligation auxiliary $\mathbf{3}$. Installation of the hdmb salicylaldehyde auxiliary onto the lysine side-chain of the fully-protected peptide-resin, ubiquitylation and hdmb auxiliary removal

amination on solid phase making this approach only really suitable for short peptides ${ }^{26}$. Salicylaldehydes, however, are an exception, forming unusually stable imines ${ }^{30}$ and a single equivalent of salicylaldehyde is generally adequate for quantitative reaction on solid-phase ${ }^{31}$. Simple demethylation of the ortho position of Tmb aldehyde converts it to a salicylaldehyde thereby assisting its easy installation onto a primary amine. Additionally, we anticipated that the ortho positioning of the hydroxyl could potentially assist $\mathrm{S}$ to $\mathrm{N}$ acyl transfer by intramolecular assistance of the proton transfer step in the ligation mechanism ${ }^{32}$. An ortho hydroxyl assists the reverse, $\mathrm{N}$ to $\mathrm{S}$ acyl migration ${ }^{33}$.

Here we show that the combination of optimised solid-phase synthesis of long peptides and an auxiliary-assisted ubiquitylation to form the isopeptide attachment enables the chemical preparation of monoubiquitylated $\mathrm{NEMO}_{\mathrm{Cozi}}$. This allows us to explore the linear ubiquitylation pathway by directly testing if HOIP can extend a linear $\mathrm{Ub}$ chain on $\mathrm{NEMO}_{\mathrm{CoZi}} \mathrm{-Ub}$ in the absence of HOIL-1 and measure the ubiquitin chain binding affinity of ubiquitylated NEMO.

\section{Results}

Auxiliary synthesis and installation. One obstacle to the use of ligation auxiliaries has been the multi-step synthesis required ${ }^{23}$. Therefore we first optimised and shortened the synthesis of the Tmb aldehyde 2 to a single easy step. It was prepared in $48 \%$ yield by substituting the nitro group of 2,3,4-trimethoxy-6-nitrobenzaldehyde 1 with $p$-methoxybenzylmercaptan in the presence of $\mathrm{KOH}$ (Fig. 2) ${ }^{19,28}$. Tmb aldehyde 2 was converted to 2hydroxy-3,4-dimethoxy-6-(4-methoxybenzylthio)benzaldehyde 3 in $76 \%$ yield by chemoselective demethylation of the 2-methoxy group. The salicylaldehyde auxiliary 3 could therefore be prepared in only two steps from commercially available nitrobenzylaldehyde $\mathbf{1}$. Importantly, there was no need to subsequently synthesize a bespoke fully-protected building block.

The addition of hdmb auxiliary was first attempted on a small model peptide (for easy monitoring by HPLC) corresponding to a fragment of the CoZi domain of mouse NEMO (NEMO ${ }_{298-308}$, ADIYKADFQAE) and containing the Lys $^{302}$ residue targeted for ubiquitylation (Fig. 3). The Lys side-chain was deprotected and a single equivalent of hdmb salicylaldehyde $\mathbf{3}$ added to the swollen peptide-resin and reduced. $\mathrm{NEMO}_{298-308} \mathrm{hdmb}$ was cleaved from the resin and the Mob group removed. Mob is a versatile protecting group removable under several conditions, in this case TMSBr was used ${ }^{26,34}$. Analytical HPLC of crude peptide samples at each step indicated that hdmb addition was complete and therefore potentially suitable for long peptides (Fig. 3).

Auxiliary-mediated ligations. We explored the ligation properties of hdmb derivatised peptides with the simplest model system, $\mathrm{NEMO}_{298-308} \mathrm{hdmb}$ and the test peptide thioester LAPAG-MPAL. 
a

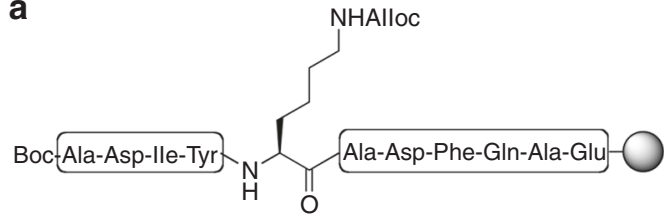

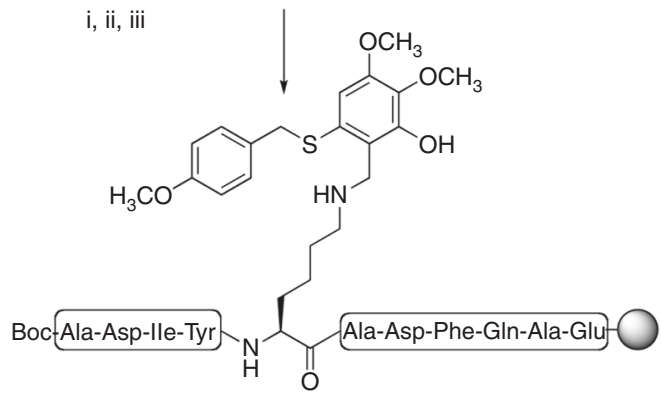

H-Ala-Asp-Ile-Tyr b
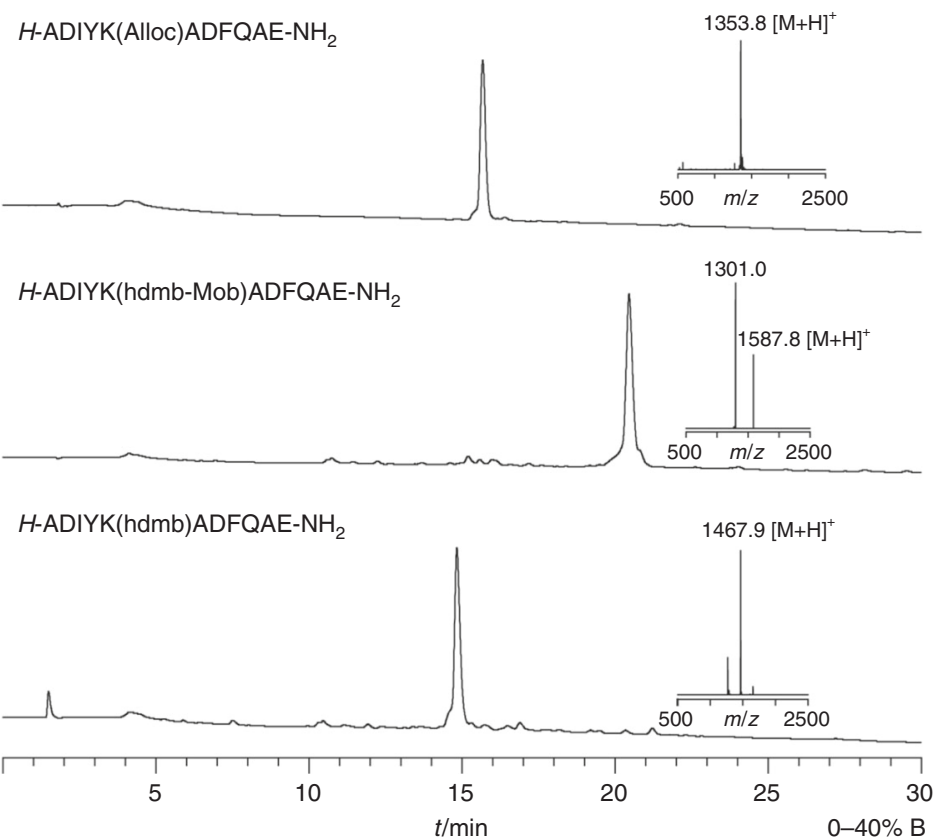

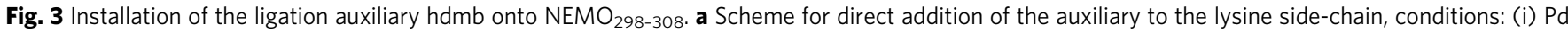
$\left(\mathrm{PPh}_{3}\right)_{4}, \mathrm{PhSiH}_{3}$, DCM (ii) 3, DMF (iii) $\mathrm{NaBH}_{4}, \mathrm{DMF}$ (iv) TFA/TES/EDT/H $\mathrm{H}_{2} \mathrm{O}$ (v) TFA/TMSBr/thioanisole/EDT. b Analytical HPLC of crude peptides and MALDI-TOF MS of pure peptides at stages of auxiliary addition. $\mathrm{H}$-ADIYK(Alloc)ADFQAE-NH $2: \mathrm{m} / z=1353.8[\mathrm{M}+\mathrm{H}]^{+}, \mathrm{Calc}$. $=1353.6$. H-ADIYK(hdmbMob)ADFQAE- $\mathrm{NH}_{2}: \mathrm{m} / \mathrm{z}=1587.8$ Calc. $=1587.7$ (a metastable ion is also observed $\mathrm{m} / \mathrm{z}=1301.0$ ). $\mathrm{H}-\mathrm{ADIYK}(\mathrm{hdmb}) \mathrm{ADFQAE}-\mathrm{NH} \mathrm{H}_{2}: \mathrm{m} / \mathrm{z}=1467.9[\mathrm{M}+$ $\mathrm{H}]^{+}$, Calc. $=1467.6$

Ligation in denaturing phosphate buffer $\mathrm{pH} 7$ was complete after $6.5 \mathrm{~h}$ (Supplementary Fig. 1). In contrast, the ligation of $\mathrm{NEMO}_{298-308} \mathrm{Tmb}$ to the test peptide under the same conditions of $\mathrm{pH}$ and concentration gave no product. After lyophilisation of the ligation mixture, the auxiliary was removed by acidolysis with no reverse $\mathrm{N}$ to $\mathrm{S}$ rearrangement detected, a concern for any extended ligation method ${ }^{27}$. The product was isolated in a combined yield for the two steps (ligation and auxiliary removal) of $55 \%$. This result encouraged us to repeat the reaction with ubiquitin.

Full-length Ubiquitin ${ }_{1-76}(\mathrm{Ub})$ was synthesized stepwise on aMeCys loaded Wang resin ${ }^{35}$ using pseudoproline and $\mathrm{Hmb}$ backbone substitution positioned throughout the sequence after Ovaa and co-workers ${ }^{36}$. The synthesis gave a crude Ub-aMeCys material of excellent quality and was purified in $28 \%$ isolated yield (Fig. 4a). a-MeCys undergoes $\mathrm{N}$ to $\mathrm{S}$ acyl transfer in presence of thiol additives to generate a thioester ${ }^{37}$. Thioester exchange with MESNa thiol to give Ub-MES thioester was complete in under $6 \mathrm{~h}$ ( $90 \%$ isolated yield). The exchange reaction was repeated with MPAA thiol to give the more activated Ub-MPAA thioester (Supplementary Fig. 3). Next we carried out ligation of the model sequence $\mathrm{NEMO}_{298-308} \mathrm{Hdmb}$ with Ub-MES thioester in denaturing phosphate buffer at a final $\mathrm{pH}$ of 6.5. The ligation was practically complete around $8 \mathrm{~h}$ (Fig. $4 \mathrm{~b}$ ). Ligation was repeated under the same conditions with Ub-MPAA and, as expected, it was faster, complete in $2 \mathrm{~h}$. The auxiliary was cleanly removed by acidolysis.

With the success of the model ligations, which showed that the hdmb auxiliary could promote efficient ligation on a Lys side- chain even below $\mathrm{pH} 7$, we addressed our goal, the ubiquitylation of mouse NEMO CoZi domain $\left(\mathrm{NEMO}_{\mathrm{Cozi}}\right)(\mathrm{PDB}$ ID:3F89). Lys $^{302}$ corresponding to human NEMO Lys ${ }^{309}$ has been identified as a position that is linearly ubiquitylated ${ }^{38}$ and also the target of bacterial ligase activity to switch off $\mathrm{NEMO}^{39}$. The structure of $\left(\mathrm{NEMO}_{\mathrm{CoZi}}\right)$ (PDB ID:3F89) as a dimer has been reported and was chosen as an ideal target for synthesis because of its size ${ }^{40}$. The 83-mer $\mathrm{NEMO}_{\mathrm{CoZi}}$ was synthesized in a single piece with Lys $^{302}$ side-chain protected with Alloc and an N-terminal biotin. After Alloc removal (Supplementary Fig. 5), the hdmb salicylaldehyde 3 was added and reductive amination, cleavage and Mob removal performed satisfactorily as established previously for the model peptide (Supplementary Figs. 6 and 7). Chemical ubiquitylation of $\mathrm{NEMO}_{\mathrm{CoZi}}$ was first performed with Ub-MES. Initially the ligation proceeded well; however, over the course of the ligation (after overnight reaction), the product aggregated. As observed previously ubiquitylation can dramatically change protein solubility ${ }^{41,42}$ and ubiquitylated $\mathrm{NEMO}_{\mathrm{CoZi}}$ appeared to be much less soluble in the ligation conditions than either of its precursors. The ligation was therefore repeated with Ub-MPAA to speed up the reaction and thereby avoid aggregation. Ligation at final pH 6.5 using $1 \mathrm{mM} \mathrm{NEMO} \mathrm{Cozi}_{\mathrm{Hdmb}}$ and 2 equivalents of Ub-MPAA was complete in under $6 \mathrm{~h}$ without aggregation. The ligation was monitored by gel electrophoresis (Fig. 5a) and hdmb removed by direct acidolysis of the crude freeze-dried ligation mixture. HPLC purification yielded $\mathrm{NEMO}_{\mathrm{CoZi}}-\mathrm{Ub}$ in $38 \%$ yield for combined steps of ligation and auxiliary removal, and gratifyingly MALDI-TOF MS gave the expected mass (Fig. 5b). The specificity of the ubiquitylation was proven by trypsin 
a
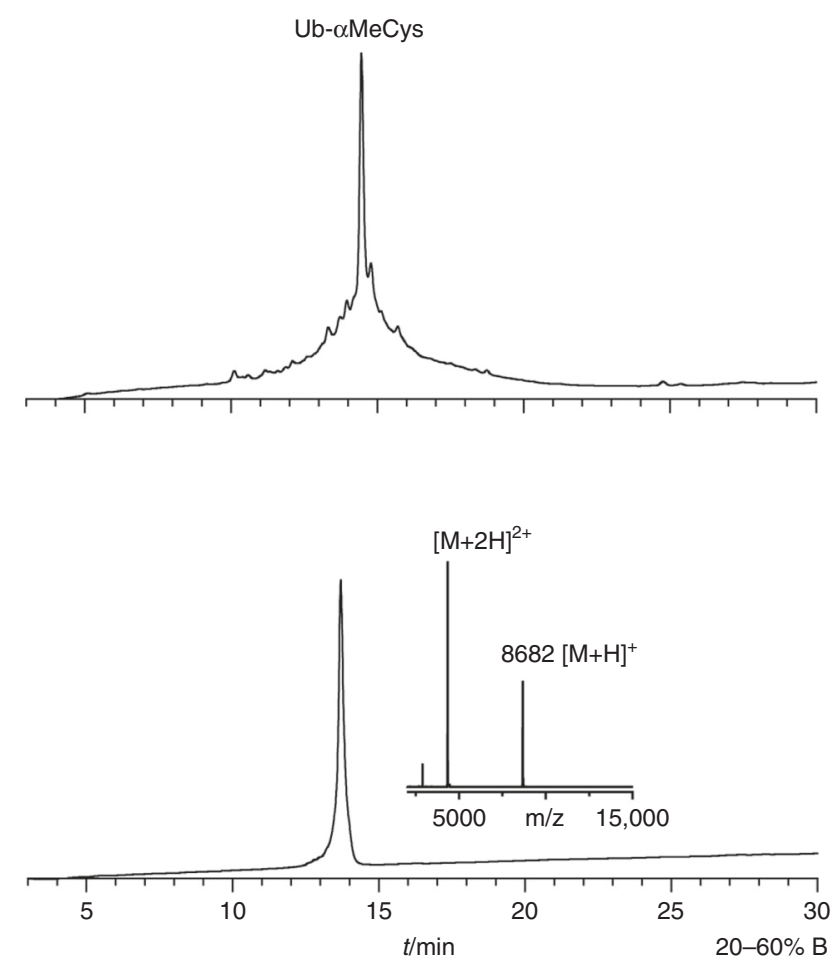
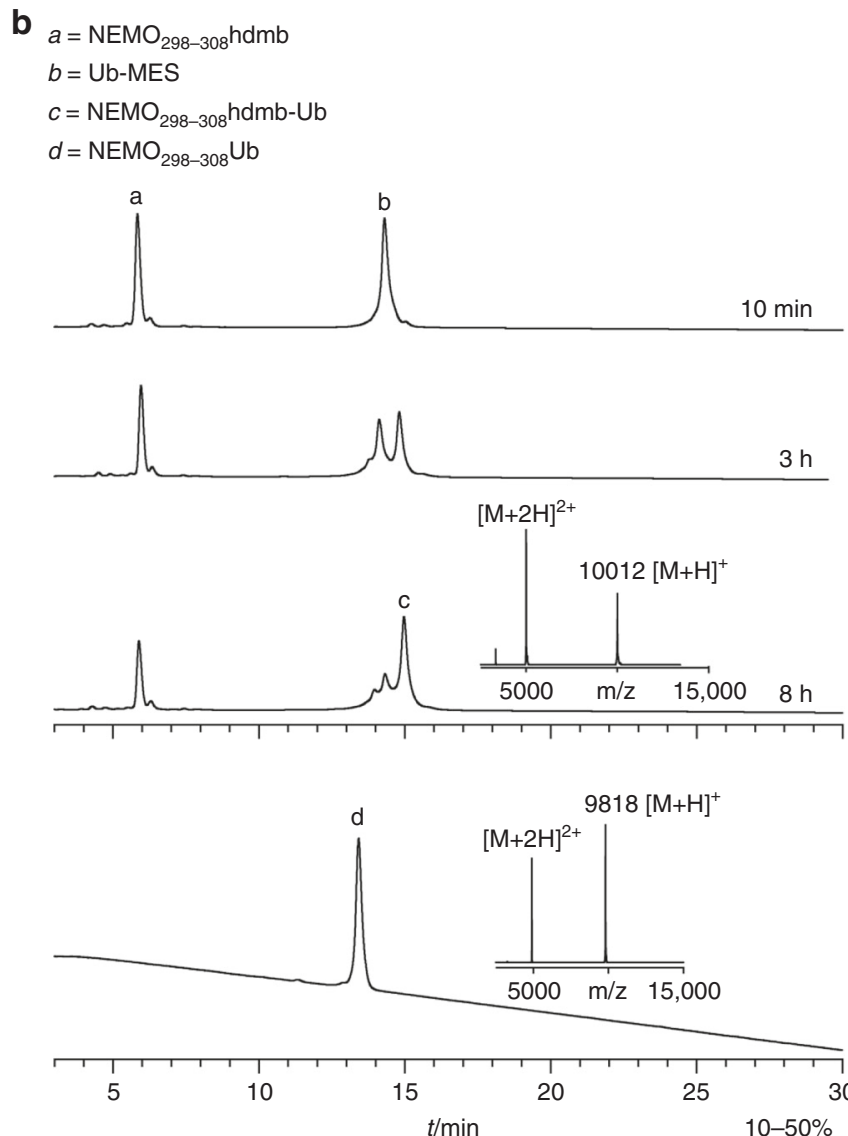

Fig. 4 Synthesis of ubiquitin- $\alpha$ MeCys and model ligation. a Analytical HPLC (RP-C18) of crude and purified Ub- $\alpha$ MeCys. MALDI-TOF MS, $m / z=8682$ $[\mathrm{M}+\mathrm{H}]^{+}$, calc. Av. $=8682$. b Model ligation of $\mathrm{NEMO}_{298-308} \mathrm{hdmb}$ with Ub-MES thioester, time-course monitoring of ligation reaction by analytical HPLC, RP-diphenyl. Bottom, analytical HPLC of $\mathrm{NEMO}_{298-308-U b}$ (after hdmb removal) (d) and MALDI-TOF MS, $\mathrm{m} / z=9818[\mathrm{M}+\mathrm{H}]^{+}, \mathrm{calc} . \mathrm{Av} .=9817$

digestion and subsequent LC-MSMS analysis. The distinctive GG tag confirmed ubiquitylation at position Lys 302 (Supplementary Fig. 8).

Folding and di-ubiquitin chain binding of NEMO $_{\mathrm{CoZi}}$ derivatives. The folding of synthetic $\mathrm{NEMO}_{\mathrm{CoZi}}$ derivatives was studied by circular dichroism. $\mathrm{NEMO}_{\mathrm{CoZi}}$ displayed far-UV CD spectra characteristic of helical secondary structure (Fig. 6a), which converts to a random coil at elevated temperature (Fig. 6b). To demonstrate that the $\alpha$-helical structure of $\mathrm{NEMO}_{\mathrm{Cozi}}$ coils together to form a dimer we determined the melting point of the protein at different concentration (Fig. 6c). The melting temperature is clearly shifting with increasing concentrations of $\mathrm{NEMO}_{\mathrm{Cozi}}$, indicating that synthetic biotinylated $\mathrm{NEMO}_{\mathrm{CoZi}}$ forms a coiled-coil dimer consistent with the crystal structure derived from bacterially expressed $\mathrm{NEMO}_{\mathrm{CoZi}}$ (PDB: ID 3F89) ${ }^{3,40}$.

We also determined $\mathrm{CD}$ spectra of synthetic ubiquitylated $\mathrm{NEMO}_{\mathrm{CoZ}}$, which displays additional secondary structure to $\mathrm{NEMO}_{\mathrm{CoZi}}$ alone (Fig. 6a). The CD spectra of NEMOCoZi-Ub closely resembles the sum of the two separate spectra of $\mathrm{NEMO}_{\mathrm{CoZi}}$ and ubiquitin, indicating that both parts, the NEMO coiled-coil as well as the ubiquitin are properly folded. Altogether, the circular dichroism data strongly suggest that our synthetic $\mathrm{NEMO}_{\mathrm{CoZi}}$ derivatives adopt the native fold of their endogenous counterparts.

NEMO CoZi domain is not only a substrate for ubiquitylation, but also binds linear Ub chains with high affinity ${ }^{3,40}$. It is believed that linear Ub binding of NEMO is required for recruitment of IKK into the TNF receptor-signalling complex (TNFRSC), which results in ubiquitylation of NEMO by LUBAC and triggers subsequent kinase activation of IKK. However, little is known about the impact of NEMO linear ubiquitylation on non-covalent complex formation. With the biotinylated synthetic material we could directly measure and compare the affinities of $\mathrm{NEMO}_{\mathrm{CoZi}}$ and $\mathrm{NEMO}_{\mathrm{CoZi}}-\mathrm{Ub}$ for linear di-Ubiquitin (di-Ub). Both NEMO derivatives were immobilized via their $\mathrm{N}$-terminal biotin and dissociation equilibrium constants were measured by biolayer interferometry. It was found that $\mathrm{NEMO}_{\mathrm{CoZi}}$ interacts with linear di-Ub with a $K_{d}$ of $25 \mu \mathrm{M}$ (Fig. 7a). This value is about 10-times higher when compared with the $\mathrm{K}_{\mathrm{d}}$ value obtained by isothermal titration calorimetry using the NEMO CoZi domain from bacterial expression systems $\left(K_{d}=2.4 \mu \mathrm{M}\right)^{3}$. The difference possibly reflects the use of distinctive techniques (which involve immobilization or not) and the use of CoZi domain constructs of different length. Interestingly, monoubiquitylated $\mathrm{NEMO}_{\mathrm{Cozi}}$ has only slightly lower affinity for linear di-Ub $\left(\mathrm{K}_{\mathrm{d}}=37 \mu \mathrm{M}\right)$ compared to unmodified $\mathrm{NEMO}_{\mathrm{CoZi}}$.

Ubiquitin elongation of $\mathrm{NEMO}_{\mathrm{CoZi}}-\mathrm{Ub}$ by the RBR domain of HOIP. Next, we set out to define the minimal catalytic complex of LUBAC required for linear ubiquitin chain elongation of NEMO primed with Ub. In order to probe if $\mathrm{NEMO}_{\mathrm{CoZi}}-\mathrm{Ub}$ can be utilised as a substrate we used purified proteins (RBR domain of HOIP, E1 and E2 ligases) from bacterial expression systems to reconstitute the ubiquitylation cascade. We used His-tagged Ub as a substrate for the chain synthesis reaction with $\mathrm{NEMO}_{\mathrm{CoZi}^{-}}$ $\mathrm{Ub}$. His-tagged $\mathrm{Ub}$, is sterically blocked at the $\mathrm{N}$-terminus and can only be utilised by LUBAC as donor Ub for chain elongation, 
but not for the synthesis of free, unanchored Ub chains. The enzymatic reaction was monitored by gel electrophoresis (Fig. 7b). The formation of di-ubiquitylated $\mathrm{NEMO}_{\mathrm{CoZi}}$ was observed showing that ubiquitin elongation is performed by HOIP alone and does not require HOIL-1 and SHARPIN.

\section{Discussion}

Our original goal was to demonstrate the practicality of our new ligation auxiliary hdmb on a challenging biological question. This was accomplished by the successful synthesis of $\mathrm{NEMO}_{\mathrm{CoZi}}-\mathrm{Ub}$. We established an expedited synthesis of hdmb salicylaldehyde (two steps) and showed its efficient post-synthesis installation onto a long peptide, the size of a typical protein domain. The

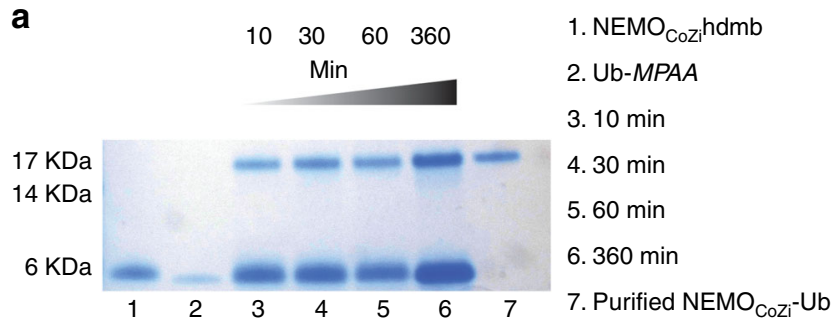

b

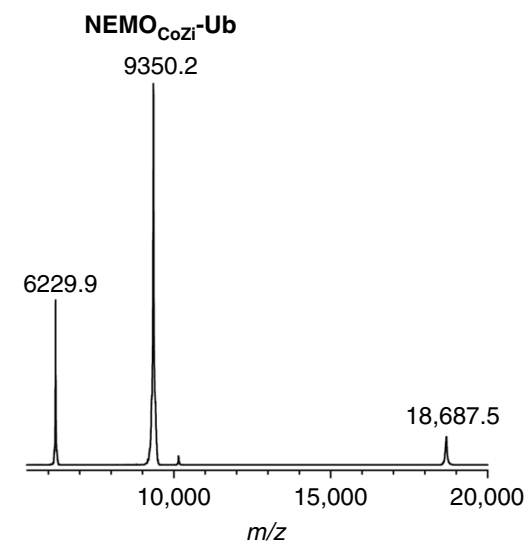

Fig. 5 Chemical ubiquitylation of $\mathrm{NEMO}_{\mathrm{Cozi}}$ with hdmb auxiliary-assisted ligation. a Time-course for auxiliary ubiquitylation of $\mathrm{NEMO}_{\mathrm{Cozi}}$ monitored by gel electrophoresis (lane 1-6). Lane 7 is the ligation product after hdmb removal and HPLC purification. b MALDI-TOF MS of NEMOCozi-Ub $\mathrm{m} / z=$ $18688[\mathrm{M}+\mathrm{H}]^{+}$, calc. Av. $m / z=18690$ ligation of two large fragments, full-length synthetic ubiquitin and $\mathrm{NEMO}_{\mathrm{CoZi}}$, at low $\mathrm{mM}$ concentration, was complete on a practical time-scale $(6 \mathrm{~h})$, which was critical in this case because of the aggregation-prone product. Interestingly, hdmb ligation occurred comfortably below $\mathrm{pH} 7$, in contrast to other auxiliaries that work in a narrow $\mathrm{pH}$ range, typically above $\mathrm{pH} 7.4^{28,43}$. The greater $\mathrm{pH}$ tolerance of hdmb was indispensable here because it avoided having to readjust the $\mathrm{pH}$ on a very small reaction volume after addition of the fragments as their TFA salts. The phenolic group of hdmb acts as an intramolecular catalyst of acyl transfer ${ }^{33}$. We considered that the higher pKa of the lysine $\varepsilon$-amine compared to the terminal $\alpha$-amine group explained the failure of Tmb to assist ligation at the lysine side-chain. The pKa difference may presumably explain why most previous attempts at auxiliaryassisted ubiquitylations were performed between $\mathrm{Gly}_{75}-\mathrm{Gly}_{76}$ of $\mathrm{Ub}$ rather than directly on the isopeptide bond even though synthesis of the lysine building block with an auxiliary attached to the side-chain is not much more challenging than for glycine.

The hdmb auxiliary was designed to be stable to the deprotection conditions of peptide cleavage from the resin but removable after ligation (the benzylamine/benzylamide safety-catch) ${ }^{25}$. In our hands removal of related backbone amide substitution such as the 2-hydroxy-4-methoxybenzyl (Hmb) becomes more difficult with increasing chain-length especially from unprotected peptides. Therefore we treated the $18.7 \mathrm{kDa} \mathrm{NEMO}_{\mathrm{CoZi}} \mathrm{hdmb}-\mathrm{Ub}$ with TFA/TMSBr to remove the hdmb auxiliary. With this method we were certain of complete removal of the auxiliary as TFA fully solvates proteins. As has been demonstrated for many other large synthetic multidomain proteins, in our hands refolding was unproblematic as monitored by CD (Fig. 6a). This acid treatment is compatible with most other PTMs besides ubiquitylation such as phosphorylation ${ }^{44}$. Although there has been a focus towards developing what are considered milder deprotection conditions we observed no problems with this acid deprotection and the improvement in installation and ligation of the auxiliary more than compensated for any theoretical disadvantage.

The fully chemically characterised $\mathrm{NEMO}_{\mathrm{CoZi}}-\mathrm{Ub}$ acted as a substrate for HOIP. This shows that the RBR domain of HOIP is sufficient to catalyse the formation of a linkage between $\mathrm{Ub}$ primed NEMO and a second molecule of Ub (Fig. 7b). Thus, in contrast to $\mathrm{ab}$ initio ubiquitylation, RBR linear chain elongation of NEMO is independent of HOIL-1. The result demonstrates that the synthesis of linear chains, which are anchored to its target protein does not require additional structural elements outside the catalytic core of HOIP. Based on our findings we suggest that
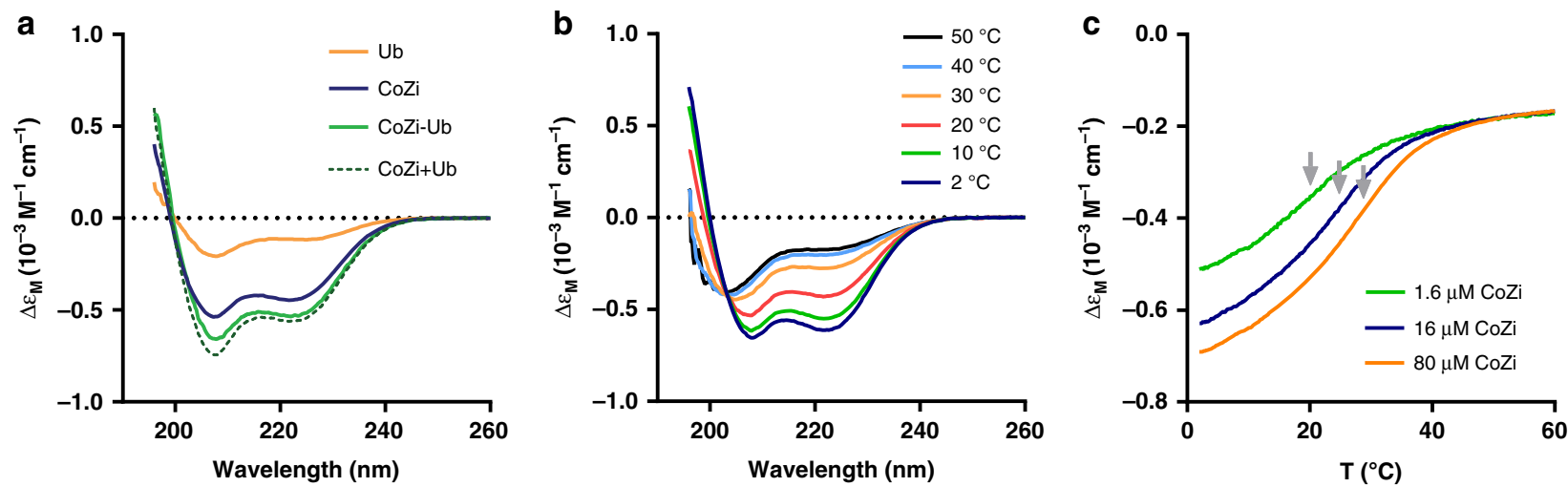

Fig. 6 Structural characterisation of $\mathrm{NEMO}_{\mathrm{Cozi}}$ and $\mathrm{NEMO}_{\mathrm{Cozi}}-\mathrm{Ub}$ by circular dichroism spectroscopy. a Far-UV CD spectra of $\mathrm{NEMO}_{\mathrm{CoZi}}, \mathrm{NEMO}_{\mathrm{Cozi}}-\mathrm{Ub}_{\mathrm{B}}$ and ubiquitin measured at $20^{\circ} \mathrm{C}$. The $\mathrm{CD}$ spectra of $\mathrm{NEMO}_{\mathrm{Cozi}}-\mathrm{Ub}$ is very similar to the the sum of the spectra of the individual components, $\mathrm{NEMO}_{\mathrm{CoZ}}$ and ubiquitin. b Far-UV CD spectra of $\mathrm{NEMO}_{\mathrm{Cozi}}(16 \mu \mathrm{M})$ at different temperatures. $\mathbf{c}$ Thermal melting curves of $\mathrm{NEMO}_{\text {Cozi }}$ measured at $222 \mathrm{~nm}$. The melting temperature (grey arrows) increases at higher concentrations of $\mathrm{NEMO}_{\text {cozir }}$, from $20.2^{\circ} \mathrm{C}$, to $24.9^{\circ} \mathrm{C}$, and to $28.5^{\circ} \mathrm{C}$ 
a
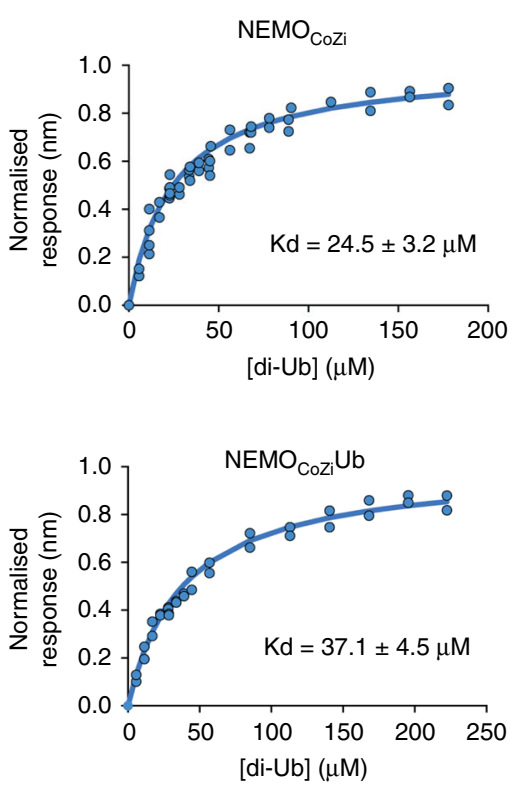

b

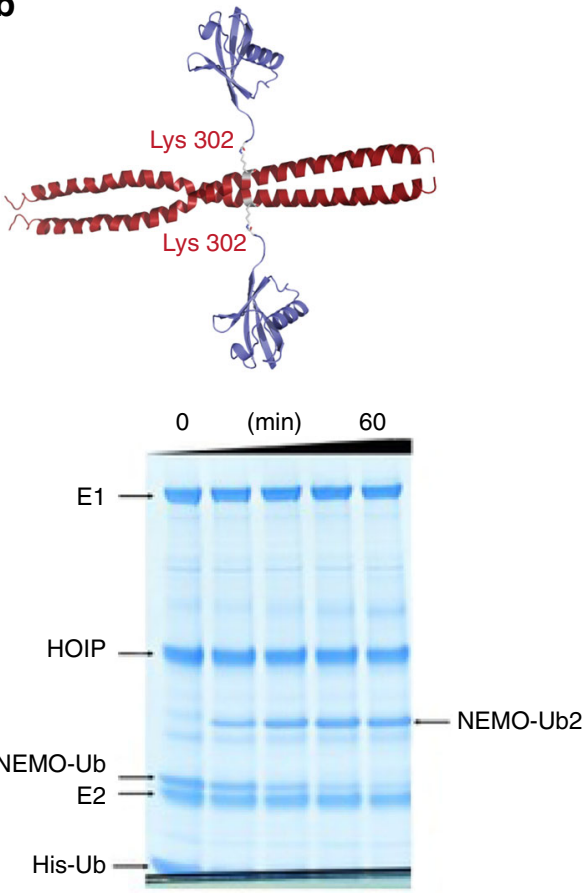

Fig. 7 Biophysical characterisation and substrate properties of $\mathrm{NEMO}_{\mathrm{Cozi}} \mathrm{Ub}$ a Biolayer interferometry measurement of binding of linear di-Ub to $\mathrm{NEMO}_{\mathrm{Cozi}}$ and $\mathrm{NEMO}_{\mathrm{Cozi}}-\mathrm{Ub}$. Data points from four independent experiments are shown. Errors on the dissociation constants represent the standard error from non-linear least square fitting to the combined datasets. $\mathbf{b}$ model of the $\mathrm{NEMO}_{\mathrm{Cozi}}-\mathrm{Ub}$ coiled-coil, time-course of linear ubiquitylation of $\mathrm{NEMO}_{\mathrm{Cozi}}$ Ub by the RBR domain of HOIP (HOIP) and E1 and E2 ligases with N-terminal His-tagged ubiquitin (His-Ub) showing the emergence of di-ubiquitylated $\mathrm{NEMO}_{\text {CoZi }}(\mathrm{NEMO}-U b 2)$

linear ubiquitylation of NEMO occurs in two stages: a priming step where Ub is attached to NEMO, which involves an enzymatic function of LUBAC outside the RBR-LDD domain of HOIP followed by a second phase of chain elongation, where $\mathrm{Ub}$ is linked to M1 of the primed $\mathrm{Ub}$, which only requires the HOIP catalytic activity.

The second phase is independent of HOIL-1 and only requires HOIP. This activity might be important for balanced NF- $\mathrm{B}$ signalling by maintaining the extent of linear $\mathrm{Ub}$ chains conjugated to NEMO thereby counteracting the deubiquitylation activity of DUBs such as Otulin or CYLD which terminate NF- $\kappa B$ activation $^{45}$. Future cell-based assays will be required to elucidate to which extent HOIL-1 independent LUBAC activity contributes to a sustained activation of the NF- $\kappa \mathrm{B}$ pathway. In addition, our biophysical experiments showed that $\mathrm{NEMO}_{\mathrm{CoZi}}$ and $\mathrm{NEMO}_{\mathrm{CoZi}^{-}}$ $\mathrm{Ub}$ have similar affinities for di-Ub. This implies that NEMO modification with ubiquitin and binding of linear ubiquitin are not mutually exclusive. We therefore suggest that LUBAC mediated activation of IKK via NEMO ubiquitylation does not require dissociation from the $\mathrm{Ub}$ binding platform of the activated receptor-signalling complex. It is interesting to note that the melting point of $\mathrm{NEMO}_{\mathrm{Cozi}}$ is shifted to higher temperature in its ubiquitylated form, thereby stabilising the coiled-coil (Supplementary Fig. 9). The increased structural rigidity of the CoZi domain might contribute to the conformational rearrangement, which takes place upon activation by M1-linked polyubiquitin ${ }^{46}$.

In summary, we have presented a short synthesis of the hdmb auxiliary and its easy addition to the lysine side-chain, enabling rapid access to site-specifically ubiquitylated NEMO. We have shown that priming and elongation are separate events located on different catalytic sites, reflecting the modular nature of the LUBAC complex. We are using this direct and specific ubiquitylation tactic to further explore the NFkB pathway. Hdmb is especially suited to three-piece ligations, required for larger targets, as the conditions of ligation are complementary and orthogonal to classical $\mathrm{NCL}^{28,47}$ and therefore potentially with mercaptolysine assisted ligation. The promising ligation properties of the hdmb auxiliary will be further explored with more sterically challenging ligations.

\section{Methods}

2-hydroxy-3,4-dimethoxy-6-(4-methoxybenzylthio) benzaldehyde 3. Initially, commercially available 2,3,4-trimethoxy-6-nitrobenzaldehyde 1 (CAS:

52978-83-3) (Fluorochem) was used. For all subsequent preparations 2,3,4-trimethoxybenzaldehyde $(20 \mathrm{~g}, 101.9 \mathrm{mmol})$ in glacial acetic acid $(50 \mathrm{~mL})$ was cooled to $-15{ }^{\circ} \mathrm{C}, 70 \%$ conc. $\mathrm{HNO}_{3}(50 \mathrm{~mL})$ was slowly added and the mixture stirred at $0^{\circ} \mathrm{C}$ for $1 \mathrm{~h}$. The reaction mixture was poured into ice-water $(350 \mathrm{~mL})$ and the yellow precipitate filtered off, washed with cold water, and dried in a vacuum desiccator. Recrystallisation yielded $\mathbf{1}(8.59 \mathrm{~g}, 35 \%)$ as pale yellow crystals, $\mathrm{mp}$ $83-84^{\circ} \mathrm{C}$ (EtOAc-hexanes). ${ }^{1} \mathrm{H}$ NMR $\left(400 \mathrm{MHz}, \mathrm{CDCl}_{3}\right): \delta 10.21(\mathrm{~s}, 1 \mathrm{H}), 7.27$ (s, 1H), 3.95 (s, 3H), $3.94(\mathrm{~s}, 6 \mathrm{H})$.

To a cold solution of $\mathbf{1}(4.83 \mathrm{~g}, 20 \mathrm{mmol})$ and 4-methoxybenzylmercaptan $(3.08$ g, $20 \mathrm{mmol})$ in DMF $(40 \mathrm{~mL})$ was added dropwise a solution of $\mathrm{KOH}(2.02 \mathrm{~g}, 36$ $\mathrm{mmol})$ in water $(5 \mathrm{~mL})$. The mixture was heated $\left(80^{\circ} \mathrm{C}, 6 \mathrm{~h}\right)$ and the resulting dark red solution poured into ice-water $(350 \mathrm{~mL})$. The brown precipitate was filtered, washed with cold water and dried. Recrystallisation yielded 2,3,4-trimethoxy-6-(4methoxybenzylthio)benzaldehyde $2(3.32 \mathrm{~g}, 48 \%)$ as light brown crystals, $\mathrm{mp}$ $150-152{ }^{\circ} \mathrm{C}$ (EtOAc-hexanes). ${ }^{1} \mathrm{H}$ NMR $\left(400 \mathrm{MHz}, \mathrm{CDCl}_{3}\right): \delta 10.32(\mathrm{~s}, 1 \mathrm{H}), 7.32$ $\left(\mathrm{q}_{\mathrm{AA}^{\prime} \mathrm{BB}^{\prime}}, J=8.7 \mathrm{~Hz}, 2 \mathrm{H}\right), 6.83\left(\mathrm{q}_{\mathrm{AA}^{\prime} \mathrm{BB}^{\prime}}, J=8.7 \mathrm{~Hz}, 2 \mathrm{H}\right), 6.56(\mathrm{~s}, 1 \mathrm{H}), 4.08(\mathrm{~s}, 2 \mathrm{H})$ $3.96(\mathrm{~s}, 3 \mathrm{H}), 3.81(\mathrm{~s}, 3 \mathrm{H}), 3.79(\mathrm{~s}, 3 \mathrm{H}), 3.77(\mathrm{~s}, 3 \mathrm{H})$.

A solution of $2(3.32 \mathrm{~g}, 9.5 \mathrm{mmol})$ in dry $\mathrm{CH}_{2} \mathrm{Cl}_{2}(190 \mathrm{~mL})$ was cooled to $0{ }^{\circ} \mathrm{C}$ and boron tribromide dimethyl sulfide complex (5.94 g, $19 \mathrm{mmol})$ added. The reaction was monitored by TLC [EtOAc-hexanes (3:7)]. After $3 \mathrm{~h}$ the bright red solution was washed with water $(100 \mathrm{~mL})$, evaporated, diluted with EtOAc (180 $\mathrm{mL})$, washed with saturated aq. $\mathrm{NaHCO}_{3}$, brine, dried $\left(\mathrm{MgSO}_{4}\right)$ and evaporated. Chromatography [EtOAc-hexanes (3:7)] yielded $3(2.41 \mathrm{~g}, 76 \%)$ as light brown crystals, mp $123-124^{\circ} \mathrm{C}$ (EtOAc-hexanes). ${ }^{1} \mathrm{H}$ NMR $\left(400 \mathrm{MHz}, \mathrm{CDCl}_{3}\right): \delta 12.19$ (s, $1 \mathrm{H}), 10.17(\mathrm{~s}, 1 \mathrm{H}), 7.04\left(\mathrm{q}_{\mathrm{AA}^{\prime} \mathrm{BB}}, J=8.6 \mathrm{~Hz}, 2 \mathrm{H}\right), 6.78\left(\mathrm{q}_{\mathrm{AA}^{\prime} \mathrm{BB}}, J=8.6 \mathrm{~Hz}, 2 \mathrm{H}\right)$, $6.49(\mathrm{~s}, 1 \mathrm{H}), 3.97(\mathrm{~s}, 2 \mathrm{H}), 3.86(\mathrm{~s}, 3 \mathrm{H}), 3.81(\mathrm{~s}, 3 \mathrm{H}), 3.76(\mathrm{~s}, 3 \mathrm{H})$ (Supplementary Fig. 10). Elemental analysis calc. $\mathrm{C}_{17} \mathrm{H}_{18} \mathrm{O}_{5} \mathrm{~S}$ : C, 61.06; H, 5.43. Found: $\mathrm{C}, 61.22$; H, 5.39 . 
Peptide synthesis. Peptides were prepared by standard automated solid-phase synthesis using DIC/HOBt activation for Fmoc/t-Bu chemistry (CS Bio 336 automated synthesizer) except for LAPAG-MPAL prepared by HF-free Boc chemistry ${ }^{44}$. Couplings of amino acids were carried out with a five-fold excess of activated amino acid for a minimum of $45 \mathrm{~min}$. Unless otherwise indicated, cleavage from the resin was performed by treatment of the peptide-resin with a cleavage cocktail containing TFA and as scavengers, triethylsilane (TES), $\mathrm{H}_{2} \mathrm{O}$, ethanedithiol (EDT) in the ratio 94.5:2.5:2.5:0.5 (v/v) for 1.5 h. The cleavage cocktail was filtered, the filtrate sparged $\left(\mathrm{N}_{2}\right)$ and the peptide precipitated $\left(\mathrm{Et}_{2} \mathrm{O}\right.$, $\mathrm{Na}$-dried, $\left.-20^{\circ} \mathrm{C}\right)$ and freeze-dried. Peptides were purified by semi-preparative HPLC on a RP-C18 column $(22 \times 250 \mathrm{~mm}$, Vydac $)$ using linear gradients of $\mathrm{CH}_{3} \mathrm{CN}$ in $0.1 \% \mathrm{TFA} / \mathrm{H}_{2} \mathrm{O}$ with a flow rate of $15 \mathrm{~mL} \cdot \mathrm{min}^{-1}$. Peptide analysis by HPLC was performed with a RP-C18 column (Phenomenex) or Diphenyl column (Vydac) using linear gradients of $\mathrm{CH}_{3} \mathrm{CN}$ in $0.1 \% \mathrm{TFA} / \mathrm{H}_{2} \mathrm{O}$ with a flow rate of $1 \mathrm{~mL} \cdot \mathrm{min}^{-1}$. HPLC gradients are given with $\mathrm{A}=0.1 \%$ TFA in $\mathrm{H}_{2} \mathrm{O}$ and $\mathrm{B}=0.1 \%$ TFA, $10 \% \mathrm{H}_{2} \mathrm{O}, 90 \% \mathrm{CH}_{3} \mathrm{CN}$. Detection was performed at $214 \mathrm{~nm}$. Peptides were characterised by MALDI-TOF MS on a BRUKER microflex using CHCA matrix (10 mg.mL $\mathrm{mL}^{-1}$ in $\mathrm{CH}_{3} \mathrm{CN} / \mathrm{H}_{2} \mathrm{O} / \mathrm{TFA}$, 50:50:0.1) or by LCMS on a Shimadzu 2010EV

Synthesis of $\mathrm{NEMO}_{\text {298-308 }}$ hdmb (H-ADIYK(hdmb)ADFQAE- $\mathrm{NH}_{2}$ ). The peptide was synthesised on Rink-amide resin $(250 \mathrm{mg}, 0.1 \mathrm{mmol})$ with standard Fmoc amino acids except for Lys ${ }^{302}$ (Fmoc-Lys(Alloc)-OH) and $\mathrm{Al}^{298}$ (Boc-Ala-OH). A sample of peptide-resin $(5 \mathrm{mg})$ was treated with TFA and scavengers and the peptide isolated as described above to check the peptide (Fig. 3). Lys $^{302}$ was deprotected by treatment of the peptide-resin with $\mathrm{Pd}\left(\mathrm{PPH}_{3}\right)_{4}(29 \mathrm{mg}, 0.025 \mathrm{mmol})$, $\mathrm{PhSiH}_{3}(308 \mu \mathrm{L}, 2.5 \mathrm{mmol})$ in dry $\mathrm{CH}_{2} \mathrm{Cl}_{2}$ under Argon. Peptide-resin was washed with $\mathrm{CH}_{2} \mathrm{Cl}_{2}$ and DMF, followed by DMF containing diethyldithiocarbamic acid sodium salt trihydrate $(0.5 \% \mathrm{w} / \mathrm{v})$, and DIEA $(0.5 \% \mathrm{v} / \mathrm{v})$ to complex out residual palladium and washed again with DMF. Auxiliary $3(33.4 \mathrm{mg}, 0.1 \mathrm{mmol})$ was added with minimum DMF to the peptide-resin $(0.1 \mathrm{mmol})$. After agitation $(15 \mathrm{~min})$ and washing (DMF), $\mathrm{NaBH}_{4}(10 \mathrm{mg}, 0.26 \mathrm{mmol})$ was added and left for $5 \mathrm{~min}$. Peptideresin was finally washed (DMF) and dried. $\mathrm{NEMO}_{298-308}$ hdmb-Mob was cleaved from the resin as described above. The crude peptide (typically $10 \mathrm{mg}$ scale) was treated for $2 \mathrm{~h}$ at $\mathrm{rt}$ with a mixture of TFA/TMSBr/thioanisole/EDT

(1:0.1:0.05:0.025; $8 \mathrm{~mL})$ to remove the Mob protecting group. TFA was removed by sparging $\left(\mathrm{N}_{2}\right)$ and the peptide precipitated $\left(\mathrm{Et}_{2} \mathrm{O}, \mathrm{Na}\right.$-dried, $\left.-20^{\circ} \mathrm{C}\right)$. Semipreparative HPLC of the pooled samples (RP-C18, $5-50 \%$ B in $30 \mathrm{~min}, 15 \mathrm{~mL} / \mathrm{min}$ ) yielded $\mathrm{NEMO}_{298-308} \mathrm{hdmb}(26 \mathrm{mg}, 16.4 \mu$ moles, $16.4 \%$, purity $>95 \%$ ). The peptide was characterised by MALDI-TOF MS in positive ion linear mode: $m / z=1467.9$ $[\mathrm{M}+\mathrm{H}]^{+}$, calc. $=1467.6$ (Fig. 3).

Ligation of $\mathbf{N E M O}_{\mathbf{2 9 8 - 3 0 8}}$ hdmb and LAPAG-MPAL. $\mathrm{NEMO}_{298-308} \mathrm{hdmb}(1 \mathrm{mg}$, $0.59 \mu \mathrm{mol}$, final concentration $5 \mathrm{mM}$ ) was dissolved in $115 \mu \mathrm{L}$ of degassed $200 \mathrm{mM}$ sodium phosphate buffer, $2 \mathrm{mM}$ EDTA, $6 \mathrm{M}$ guanidine. $\mathrm{HCl}, 10 \mathrm{mg} / \mathrm{mL}$ MPAA, $15 \mathrm{mg} / \mathrm{mL}$ TCEP, $\mathrm{pH}$ 7.5. This solution was added to LAPAG-MPAL $(0.64 \mathrm{mg}$, $0.86 \mu$ mole, final concentration $7.5 \mathrm{mM})$ and the mixture was kept at $40^{\circ} \mathrm{C}$. The final $\mathrm{pH}$ of the reaction mixture was 7 . The ligation was monitored by analytical HPLC and was complete in $6 \mathrm{~h} 30 \mathrm{~min}$ (Supplementary Fig. 1). The reaction mixture was freeze-dried. The ligation product $\mathrm{NEMO}_{298-308} \mathrm{hdmb}-\mathrm{LAPAG}$, isolated from analytical HPLC, was characterized by MALDI-TOF MS in the positive ion reflector mode: $m / z=1876.3[\mathrm{M}+\mathrm{H}]^{+}$, calc $=1876.9$. The lyophilized mixture was treated at $\mathrm{rt}$ for $1 \mathrm{~h} 30 \mathrm{~min}$ with $1 \mathrm{~mL}$ of TFA/TMSBr/thioanisole/EDT (1:0.05:0.05:0.025) to remove hdmb. The TFA was removed by sparging under a stream of $\mathrm{N}_{2}$ and the peptides precipitated in cold $\mathrm{Et}_{2} \mathrm{O}$. Purification by HPLC (RPC18, 0 to $20 \% \mathrm{~B}, 1 \mathrm{~mL} / \mathrm{min}$ ) yielded $\mathrm{NEMO}_{298-308-\mathrm{LAPAG}}(0.62 \mathrm{mg}, 0.325 \mu$ moles, $55 \%$ overall yield for combined ligation reaction and auxiliary removal, purity $>$ 95\%). The peptide was characterized by MALDI-TOF MS in the positive ion reflector mode: $m / z=1679.3[\mathrm{M}+\mathrm{H}]^{+}$, calc $=1679.8$.

\section{Synthesis of Ub- $\alpha$ MeCys. (H-MQIFVKTLTGKTITLEVEPSDTIENVKAKIQDKE} GIPPDQQRLIFAGKQLEDGRTLSDYNIQKESTLHLVLRLRGGaMeC-OH): The peptide was synthesized as described above on Wang resin $(0.1 \mathrm{mmol}, 500 \mathrm{mg})$ loaded with Fmoc- $\alpha \mathrm{MeCys}(\mathrm{Trt})-\mathrm{OH}^{35}$, with the addition of pseudoproline or Hmbglycine at the positions indicated in bold in the sequence above (after El Oualid et al. ${ }^{36}$ ) yielding $3.2 \mathrm{~g}$ of dried peptide-resin. Cleavage was performed as previously described (typically, $5 \mathrm{~mL}$ TFA cleavage mixture was used to cleave $100 \mathrm{mg}$ peptide-resin, $3.125 \mu \mathrm{mol}$ ). Crude peptide was dissolved in $20 \%$ buffer B in A and freeze-dried. Purification by HPLC (RP-C18, 25-45\% B in $30 \mathrm{~min}, 15 \mathrm{~mL} / \mathrm{min}$ ) yielded Ub-aMeCys $(9.1 \mathrm{mg}$ obtained from $100 \mathrm{mg}$ peptide-resin, $0.895 \mu$ mole, $28.6 \%$ yield, purity $>95 \%$ ). The peptide was characterized by MALDI-TOF MS in the positive ion linear mode: $\mathrm{m} / \mathrm{z}=$ $8682[\mathrm{M}+\mathrm{H}]^{+}$, calc $=8682$ (Fig. 4$)$.

Synthesis of Ub-MES thioester by $N, S$ acyl transfer and thioester exchange from Ub- $\alpha M e C y s$. Pure Ub- $\alpha$ MeCys $(3.8 \mathrm{mg}, 0.374 \mu \mathrm{mol}$, final concentration $0.1 \mathrm{mM}$ ) was dissolved in degassed $200 \mathrm{mM}$ sodium phosphate buffer, $2 \mathrm{mM}$ EDTA, $6 \mathrm{M}$ guanidine. $\mathrm{HCl}, 5 \mathrm{mg} / \mathrm{mL}$ TCEP $(17.5 \mathrm{mM}), 100 \mathrm{mg} / \mathrm{mL} \mathrm{MesNa}$ $(610 \mathrm{mM}), \mathrm{pH} 4.5$ to 5 . The reaction mixture was kept at $50^{\circ} \mathrm{C}$. Ub-MES and starting material Ub-aMeCys co-eluted on all HPLC columns and gradients attempted. Monitoring the reaction was possible by treatment of small samples of the reaction mixture with hydrazine, the hydrazide product formed from UbMES thioester was separable on C18 and indicated the progress of the reaction The reaction was also monitored by LC-MS and was complete after $7 \mathrm{~h}$. Purification by HPLC (RP-C18, 25-45\% B in $30 \mathrm{~min}, 15 \mathrm{~mL} / \mathrm{min}$ ) yielded Ub-MES thioester $(3.5 \mathrm{mg}, 0.345 \mu$ mole, $90 \%$ yield). The peptide was characterized by MALDI-TOF MS in the positive ion linear mode: $m / z=8689[\mathrm{M}+\mathrm{H}]^{+}$, calc $=$ 8689 (Supplementary Fig. 2).

Synthesis of Ub-MPAA thioester by $N, S$ acyl transfer and thioester exchange from Ub- $\alpha$ MeCys. Pure Ub- $\alpha$ MeCys $(7.1 \mathrm{mg}, 0.699 \mu \mathrm{mol}$, final concentration $0.2 \mathrm{mM}$ ) was dissolved in $3.5 \mathrm{~mL}$ degassed $200 \mathrm{mM}$ sodium phosphate buffer, $2 \mathrm{mM}$ EDTA, $6 \mathrm{M}$ guanidine. $\mathrm{HCl}, 10 \mathrm{mg} / \mathrm{mL}$ TCEP $(17.5 \mathrm{mM}), 25 \mathrm{mg} / \mathrm{ml}$ MPAA $(150 \mathrm{mM}), \mathrm{pH} 4.5-5$. The reaction mixture was kept for $8 \mathrm{~h}$ at $50^{\circ} \mathrm{C}$. In this case the exchange reaction could be easily monitored by analytical HPLC (Supplementary Fig. 3). TFA (50 $\mu \mathrm{L}$ ) was added to acidify and quench the reaction mixture (final $\mathrm{pH}$ 2) and the mixture was extracted with $\mathrm{Et}_{2} \mathrm{O}$ to remove the MPAA thiol additive. Purification by HPLC of the aqueous phase (RP-C18, 30-45\% B in $30 \mathrm{~min}, 5 \mathrm{~mL} / \mathrm{min}$ ) yielded Ub-MPAA thioester ( $2.4 \mathrm{mg}, 0.235 \mu$ mole, $34 \%$ yield). The peptide was characterized by MALDI-TOF MS in the positive ion linear mode: $m / z=8715[\mathrm{M}+\mathrm{H}]^{+}$, calc $=8715$ (Supplementary Fig. 4)

Ligation of $\mathbf{N E M O}_{\mathbf{2 9 8 - 3 0 8}}$ hdmb and Ub-MES. $\mathrm{NEMO}_{298-308} \mathrm{hdmb}(0.34 \mathrm{mg}$, $0.2 \mu \mathrm{mol}$, final concentration $4 \mathrm{mM}$,) was dissolved in $50 \mu \mathrm{L}$ of degassed $200 \mathrm{mM}$ sodium phosphate buffer, $2 \mathrm{mM}$ EDTA, $6 \mathrm{M}$ guanidine. $\mathrm{HCl}, 15 \mathrm{mg} / \mathrm{mL}$ TCEP, $\mathrm{pH}$ 7.5. This solution was added to Ub-MES thioester $(1 \mathrm{mg}, 0.1 \mu \mathrm{mol}$, final concentration $2 \mathrm{mM}$ ) and the mixture kept at $40^{\circ} \mathrm{C}$. The final $\mathrm{pH}$ of the reaction mixture was 6.5. The ligation was monitored by HPLC and was complete around $8 \mathrm{~h}$ (Fig. 4). The mixture was freeze-dried. The ligation product $\mathrm{NEMO}_{298-308} \mathrm{hdmb}-\mathrm{Ub}$, isolated from analytical HPLC, was characterised by MALDI-TOF MS in the positive ion linear mode: $m / z=10012[\mathrm{M}+\mathrm{H}]^{+}$, calc $=$ 10015.5. The lyophilised mixture was treated for $1 \mathrm{~h} 30 \mathrm{~min}$ at $\mathrm{rt}$ with $1 \mathrm{~mL}$ of TFA/ TMSBr/thioanisole/EDT (1:0.05:0.05:0.025). The TFA was removed by sparging under a stream of $\mathrm{N}_{2}$ and the peptides precipitated in cold $\mathrm{Et}_{2} \mathrm{O}$. Purification by HPLC (Diphenyl, $10-50 \% \mathrm{~B}$ in $30 \mathrm{~min}, 1 \mathrm{~mL} / \mathrm{min}$ ) yielded $\mathrm{NEMO}_{298-308}-\mathrm{Ub}$ $(0.65 \mathrm{mg}, 0.057 \mu$ moles, $58 \%$ overall yield for combined ligation and auxiliary removal, purity $>98 \%$ ). The peptide was characterised by MALDI-TOF MS in the positive ion linear mode: $m / z=9818[\mathrm{M}+\mathrm{H}]^{+}$, calc. Av. $=9817$ (Fig. 4).

Ligation of $\mathbf{N E M O}_{\mathbf{2 9 8 - 3 0 8}}$ hdmb and Ub-MPAA. $\mathrm{NEMO}_{298-308} \mathrm{hdmb}(0.6 \mathrm{mg}$, $0.35 \mu \mathrm{mol}$, final concentration $2 \mathrm{mM}$ ) was dissolved in $177 \mu \mathrm{L}$ of degassed $200 \mathrm{mM}$ sodium phosphate, $2 \mathrm{mM}$ EDTA, $6 \mathrm{M}$ guanidine. $\mathrm{HCl}, 15 \mathrm{mg} / \mathrm{mL}$ TCEP, $0.5 \mathrm{mg} / \mathrm{mL}$ MPAA, pH 7.5. $40 \mu \mathrm{L}$ of this solution was added to Ub-MPAA thioester $(0.41 \mathrm{mg}$, $0.04 \mu \mathrm{mol}$, final concentration $1 \mathrm{mM}$ ) and the mixture was kept at $40^{\circ} \mathrm{C}$. The final $\mathrm{pH}$ of the reaction mixture was 6.9. The ligation was complete in $2 \mathrm{~h}$. Removal of the auxiliary was performed as previously described.

Synthesis of NEMO cozi $_{\text {hdmb. (Biotin-EDLRQQLQQAEEALVAKQELIDKLKEE }}$ AEQHKIVMETVPVLKAQADIYK(hdmb)ADFQAERHAREKLVEKKEYLQEQLE QLQREFNKL- $\mathrm{NH}_{2}$ ): The peptide was synthesised on Rink-amide ChemMatrix resin (Aldrich) $(100 \mathrm{mg}, 0.05 \mathrm{mmol})$ with standard Fmoc amino acids except for Lys $^{302}$ (Fmoc-Lys(Alloc)-OH). The weight of the dried peptide-resin at completion of the synthesis was $730 \mathrm{mg}$. Alloc removal was performed as described above using $\mathrm{Pd}\left(\mathrm{PPh}_{3}\right)_{4}(15 \mathrm{mg}, 0.013 \mathrm{mmol}), \mathrm{PhSiH}_{3}(150 \mu \mathrm{L}, 1.22 \mathrm{mmol})$ in dry $\mathrm{CH}_{2} \mathrm{Cl}_{2}$ $(10 \mathrm{~mL})$. A sample of the peptide-resin was cleaved and analysed by HPLC and MALDI-TOF MS (Supplementary Fig. 5). To the peptide-resin $(0.025 \mathrm{mmol})$ in minimal DMF (swelling volume) was added auxiliary $3(15 \mathrm{mg}, 0.045 \mathrm{mmol})$ followed by treatment with $\mathrm{NaBH}_{4}(38 \mathrm{mg}, 1 \mathrm{mmol}$ ) as described above (Supplementary Fig. 6). The peptide was cleaved from the resin, purified by HPLC (RPC18, $20-60 \%$ B in $30 \mathrm{~min}, 15 \mathrm{~mL} / \mathrm{min})$ yielding $\mathrm{NEMO}_{\mathrm{CoZi}} \mathrm{hdmb}-\mathrm{Mob}(9.4 \mathrm{mg}$, $0.772 \mu \mathrm{mole}, 3 \%)$ and characterized by LC-MS $\left(\mathrm{m} / z=10462[\mathrm{M}+\mathrm{H}]^{+}\right.$, calc $=$

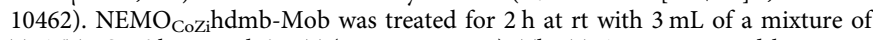
TFA/TMSBr/thioanisole/EDT (1:0.1:0.05:0.025). The TFA was removed by sparging $\left(\mathrm{N}_{2}\right)$ and the peptide precipitated $\left(\mathrm{Et}_{2} \mathrm{O}, \mathrm{Na}\right.$-dried, $\left.-20^{\circ} \mathrm{C}\right)$. Purification by HPLC (RP-C18, 20-60\% B in $30 \mathrm{~min}, 15 \mathrm{~mL} / \mathrm{min}$ ) yielded $\mathrm{NEMO}_{\mathrm{Cozi}} \mathrm{hdmb}$ ( $4.8 \mathrm{mg}, 0.398 \mu$ mole, $51.5 \%$ yield, purity $>95 \%$ ). The peptide was characterised by LCMS: $m / z=10342[\mathrm{M}+\mathrm{H}]^{+}$, calc. Av. $=10342$ (Supplementary Fig. 7).

\section{Ligation of $\mathbf{N E M O}_{\mathrm{Coz}}$ hdmb and Ub-MPAA thioester. $\mathrm{NEMO}_{\mathrm{Cozi}} \mathrm{hdmb}$} $(1.32 \mathrm{mg}, 0.1085 \mu \mathrm{mol}$, final concentration $1 \mathrm{mM}$ ) was dissolved in $100 \mu \mathrm{L}$ of degassed $200 \mathrm{mM}$ sodium phosphate, $2 \mathrm{mM}$ EDTA, $6 \mathrm{M}$ guanidine. $\mathrm{HCl}, 15 \mathrm{mg} /$ $\mathrm{mL}$ TCEP, $0.5 \mathrm{mg} / \mathrm{mL}$ MPAA, $\mathrm{pH}$ 7.5. This solution was added to Ub-MPAA thioester $(1.39 \mathrm{mg}, 0.134 \mu \mathrm{mol})$ and the mixture was kept at $40^{\circ} \mathrm{C}$. After $2 \mathrm{~h}$, further Ub-MPAA thioester $(0.5 \mathrm{mg})$ was added. The final $\mathrm{pH}$ of the ligation mixture was 6.5. The ligation was monitored by gel electrophoresis (Fig. 5a), After $6 \mathrm{~h}$, the reaction mixture was diluted with $100 \mu \mathrm{L} \mathrm{H}_{2} \mathrm{O}$ and freeze-dried. It was treated for $2 \mathrm{~h}$ with $150 \mu \mathrm{L}$ of TFA/TMSBr/thioanisole/EDT

(1:0.05:0.05:0.025). TFA was removed by sparging under a stream of $\mathrm{N}_{2}$ and the protein precipitated in cold $\mathrm{Et}_{2} \mathrm{O}$. The crude mixture was dissolved in $150 \mu \mathrm{L}$ of 
degassed $200 \mathrm{mM}$ sodium phosphate, $2 \mathrm{mM}$ EDTA, $6 \mathrm{M}$ guanidine. $\mathrm{HCl}, 5 \mathrm{mg} /$ $\mathrm{mL}$ TCEP and purified by HPLC (RP-C18, 20-55\% B in $30 \mathrm{~min}, 1 \mathrm{~mL} / \mathrm{min}$ ). To calculate the yield, the ligation was repeated in the same conditions using NEMO $_{\text {Cozi }}$ hdmb $(2.15 \mathrm{mg}, 0.177 \mu \mathrm{mol})$ and Ub-MPAA thioester $(3.5 \mathrm{mg}, 0.34$ $\mu \mathrm{mol})$. Auxiliary removal and HPLC purification yielded $\mathrm{NEMO}_{\mathrm{Cozi}}-\mathrm{Ub}(1.46$ $\mathrm{mg}, 0.0667 \mu$ moles, $38 \%$ overall yield for combined ligation and auxiliary removal). $\mathrm{NEMO}_{\mathrm{CoZi}}-\mathrm{Ub}$ was characterised by MALDI-TOF MS in the positive ion linear mode: $m / z=18688[\mathrm{M}+\mathrm{H}]^{+}$, calc. Av. $=18690$. (Fig. $5 b$ ).

LC-MSMS analysis of NEMO Cozi- $^{-U b}$. $\mathrm{NEMO}_{\mathrm{CoZi}}-\mathrm{Ub}$ was resuspended in $50 \mathrm{mM}$ $\mathrm{NH}_{4} \mathrm{HCO}_{3}$ and digested o/n using trypsin. Digested peptides were dried using a centrifugal SpeedVac and resuspended in MS solvent ( $\left.3 \% \mathrm{CH}_{3} \mathrm{CN}, 0.1 \% \mathrm{TFA}\right)$. Tryptic peptides were analysed on a Q Exactive coupled to an RSLCnano3000 (Thermo Scientific). Peptides were resolved using a $50 \mathrm{~cm}$ EASYspray column with a gradient rising from 3 to $40 \% \mathrm{CH}_{3} \mathrm{CN}$ over $23 \mathrm{~min}$. MS spectra were acquired from $\mathrm{m} / \mathrm{z} 300-1500$ with peptides selected for fragmentation in a DDA fashion. MSMS spectra were acquired at 17,500 fwhm. Raw files were processed in PEAKS studio using the PEAKS search engine. Data was searched against a database consisting of the synthetic NEMO sequence in an E.coli K12 database and a database of common contaminants. A PEAKS PTM search was performed with confident modification sites requiring a minimum ion intensity of $5 \%$ (Supplementary Fig 8).

Circular dichroism measurements. CD spectra and melting curves were recorded on a Jasco J-815 spectropolarimeter fitted with a cell holder thermostatted by a CDF-426S Peltier unit. CD measurements were made in PBS buffer pH 7.4 using fused silica cuvettes with 1-mm or 10-mm path lengths (Hellma, Germany).

Far-UV CD spectra were recorded with $2 \mathrm{~nm}$ bandwidth and baseline corrected by subtraction of the appropriate buffer spectrum. CD intensities are presented as the $\mathrm{CD}$ absorption coefficient calculated on a molar basis $\left(\Delta \varepsilon_{\mathrm{M}}\right)^{48}$. Secondary structure content was estimated by methods described by Sreerama and Woody ${ }^{49}$. Thermal unfolding curves were obtained by monitoring the ellipticity at $222 \mathrm{~nm}$ using 1 - or $10-\mathrm{mm}$ path length cuvettes and a heating rate of $2{ }^{\circ} \mathrm{C} / \mathrm{min}$ over the temperature range $2-80^{\circ} \mathrm{C}$. The transition mid-point temperature was estimated from the point of inflection, by determining the maximum of the first derivative of the melting curves.

Di-Ub binding measurements. Di-Ub binding to immobilized $\mathrm{NEMO}_{\mathrm{CoZi}}$ and $\mathrm{NEMO}_{\mathrm{CoZi}}$-Ub were measured on an Octet RED biolayer interferometer (Pall ForteBio Corp., Menlo Park, CA, USA). The Biotinylated $\mathrm{NEMO}_{\mathrm{Cozi}}$ was immobilized on streptavidin biosensors (Pall ForteBio Corp., Menlo Park, CA, USA) at a concentration of $\sim 2 \mu \mathrm{g} / \mathrm{mL}$. The binding of di-Ub (at 2-225 $\mu \mathrm{M}$ ) to immobilized NEMO was measured at $25^{\circ} \mathrm{C}$ with a 100 second association step followed by a $100 \mathrm{~s}$ dissociation step. The buffer was $10 \mathrm{mM}$ HEPES (pH 7.4), $150 \mathrm{mM} \mathrm{NaCl}$, $3 \mathrm{mM}$ EDTA and $0.005 \%$ Tween-20. The equilibrium dissociation constant was determined by analysis of the variation of the instrument response as a function of di-Ub concentration (Fig. 7a).

Protein expression and purification. Human Ubel and ubiquitin were cloned into pET-24 and expressed in BL21(DE3). Proteins were isolated by Ni affinity chromatography and subsequently purified by anion exchange chromatography followed by size exclusion chromatography (Superdex S75/S200). Human UBE2D1was cloned into pET-49 and HOIP-RBR (residues 697-1072) was cloned into pGex-6P1. After expression in BL21(DE3) proteins were isolated by GST affinity chromatography. The GST fusion was cleaved with PreScission Protease and subsequently removed by size exclusion chromatography (Superdex S75/S200). All purification steps were monitored by SDS gel electrophoresis. The protein concentrations were determined by UV-VIS spectroscopy at $280 \mathrm{~nm}$ using theoretical extinction coefficients calculated by ProtParam (http://web.expasy.org/ protparam/) Purified samples were concentrated and stored in $50 \mathrm{mM}$ HEPES $\mathrm{pH}$ 7.4, $150 \mathrm{mM} \mathrm{NaCl}$ and $1 \mathrm{mM}$ DTT.

In vitro ubiquitylation assay. $1 \mu \mathrm{M}$ Ube1, $5 \mu \mathrm{M}$ UBE2D1, $5 \mu \mathrm{M}$ of HOIP-RBR, $20 \mu \mathrm{M}$ His-Ub, and $10 \mu \mathrm{M}$ synthetic $\mathrm{NEMO}_{\mathrm{CoZi}^{-}} \mathrm{Ub}$ were mixed in $50 \mathrm{mM}$ HEPES $\mathrm{pH} 7.5,150 \mathrm{mM} \mathrm{NaCl}$ and $20 \mathrm{mM} \mathrm{MgCl}_{2}$. $\mathrm{NEMO}_{\mathrm{CoZi}^{-}} \mathrm{Ub}$ ubiquitylation with HisUb was started by adding $10 \mathrm{mM}$ ATP. The reaction was incubated at $25^{\circ} \mathrm{C}$ for $1 \mathrm{~h}$ and samples were taken at set time intervals ( 0 min (without ATP), $5 \mathrm{~min}, 15 \mathrm{~min}$, $30 \mathrm{~min}, 60 \mathrm{~min}$ ), quenched with DTT and analysed by SDS-PAGE (Fig. 7b).

\section{Data availability}

All data supporting the findings of this study, including compound characterization, are available within the paper and its supplementary information files, or from the corresponding authors on request.

Received: 3 January 2019 Accepted: 19 August 2019

Published online: 19 September 2019

\section{References}

1. Pickart, C. M. \& Fushman, D. Polyubiquitin chains: polymeric protein signals. Curr. Opin. Chem. Biol. 8, 610-616 (2004).

2. Walczak, H., Iwai, K. \& Dikic, I. Generation and physiological roles of linear ubiquitin chains. BMC Biol. 10, 23 (2012).

3. Ivins, F. J. et al. NEMO oligomerization and its ubiquitin-binding properties. Biochem. J. 421, 243-251 (2009).

4. Smit, J. J. \& Sixma, T. K. RBR E3-ligases at work. EMBO Rep. 15, 142-154 (2014).

5. Stieglitz, B., Morris-Davies, A. C., Koliopoulos, M. G., Christodoulou, E. \& Rittinger, K. LUBAC synthesizes linear ubiquitin chains via a thioester intermediate. EMBO Rep. 13, 840-846 (2012).

6. Stieglitz, B. et al. Structural basis for ligase-specific conjugation of linear ubiquitin chains by HOIP. Nature 503, 422-426 (2013).

7. Ikeda, F. et al. SHARPIN forms a linear ubiquitin ligase complex regulating NF- $\kappa$ B activity and apoptosis. Nature 471, 637-641 (2011).

8. Smit, J. J. et al. Target specificity of the E3 ligase LUBAC for ubiquitin and NEMO relies on different minimal requirements. J. Biol. Chem. 288, 31728-31737 (2013)

9. Bondalapati, S., Jbara, M. \& Brik, A. Expanding the chemical toolbox for the synthesis of large and uniquely modified proteins. Nat. Chem. 8, 407-418 (2016).

10. David, Y. \& Muir, T. W. Emerging chemistry strategies for engineering native chromatin. J. Am. Chem. Soc. 139, 9090-9096 (2017).

11. Mali, S. M., Singh, S. K., Eid, E. \& Brik, A. Ubiquitin signaling: chemistry comes to the rescue. J. Am. Chem. Soc. 139, 4971-4986 (2017).

12. Ajish Kumar, K. S., Haj-Yahya, M., Olschewski, D., Lashuel, H. A. \& Brik, A. Highly efficient and chemoselective peptide ubiquitylation. Angew. Chem. Int Ed. Engl. 121, 8090-8094 (2009).

13. Virdee, S. et al. Traceless and site-specific ubiquitination of recombinant proteins. J. Am. Chem. Soc. 133, 10708-10711 (2011).

14. Van Tilburg, G. B., Elhebieshy, A. F. \& Ovaa, H. Synthetic and semi-synthetic strategies to study ubiquitin signaling. Curr. Opin. Struct. Biol. 38, 92-101 (2016).

15. McGinty, R. K., Kim, J., Chatterjee, C., Roeder, R. G. \& Muir, T. W. Chemically ubiquitylated histone $\mathrm{H} 2 \mathrm{~B}$ stimulates hDot1L-mediated intranucleosomal methylation. Nature 453, 812-816 (2008).

16. Bello, C., Wang, S., Meng, L., Moremen, K. W. \& Becker, C. F. A PEGylated photocleavable auxiliary mediates the sequential enzymatic glycosylation and native chemical ligation of peptides. Angew. Chem. Int. Ed. Engl. 54, 7711-7715 (2015).

17. Botti, P., Carrasco, M. R. \& Kent, S. B. Native chemical ligation using removable $\mathrm{Na}$-(1-phenyl-2-mercaptoethyl) auxiliaries. Tetrahedron Lett. 42, 1831-1833 (2001).

18. Weller, C. E. et al. Aromatic thiol-mediated cleavage of $\mathrm{N}-\mathrm{O}$ bonds enables chemical ubiquitylation of folded proteins. Nat. Commun. 7, 12979 (2016).

19. Macmillan, D. \& Anderson, D. W. Rapid synthesis of acyl transfer auxiliaries for cysteine-free native glycopeptide ligation. Org. lett. 6, 4659-4662 (2004).

20. Yang, R., Bi, X., Li, F., Cao, Y. \& Liu, C.-F. Native chemical ubiquitination using a genetically incorporated azidonorleucine. Chem. Commun. 50, 7971-7974 (2014).

21. Pan, M. et al. Quasi-racemic X-ray structures of K27-linked ubiquitin chains prepared by total chemical synthesis. J. Am. Chem. Soc. 138, 7429-7435 (2016).

22. $\mathrm{Xu}, \mathrm{L}$. et al. Chemical synthesis of natural polyubiquitin chains through auxiliary-mediated ligation of an expressed ubiquitin isomer. Org. Lett. 20, 329-332 (2018).

23. Tang, S. et al. Practical chemical synthesis of atypical ubiquitin chains by using an isopeptide-linked Ub isomer. Angew. Chem. Int. Ed. Engl. 56, 13333-13337 (2017).

24. Virdee, S., Ye, Y., Nguyen, D. P., Komander, D. \& Chin, J. W. Engineered diubiquitin synthesis reveals Lys29-isopeptide specificity of an OTU deubiquitinase. Nat. Chem. biol. 6(10), 750-757 (2010).

25. Offer, J., Boddy, C. \& Dawson, P. E. Extending synthetic access to proteins with a removable acyl transfer auxiliary. J. Am. Chem. Soc. 124, 4642-4646 (2002).

26. Wu, B. et al. Building complex glycopeptides: development of a cysteine-free native chemical ligation protocol. Angew. Chem. Int. Ed. Engl. 45, 4116-4125 (2006).

27. Macmillan, D. Evolving strategies for protein synthesis converge on native chemical ligation. Angew. Chem. Int Ed. Engl. 45, 7668-7672 (2006).

28. Burlina, F. et al. Orthogonal ligation: a three-piece assembly of a PNA-peptide-PNA conjugate. Chem Commun. 24, 2785-2787 (2008).

29. Chai, H. et al. N-Linked glycosyl auxiliary-mediated native chemical ligation on aspartic acid: application towards N-glycopeptide synthesis. Angew. Chem. Int. Ed. Engl. 55, 10363-10367 (2016).

30. Flinn, N. S., Quibell, M., Turnell, W. G., Monk, T. P. \& Ramjee, M. K. Novel chemoselective linkage chemistry toward controlled loading of ligands to 
proteins through in situ real-time quantification of conjugate formation. Bioconj. Chem. 15, 1010-1020 (2004).

31. Abdel-Aal, A.-B. M., Papageorgiou, G., Quibell, M. \& Offer, J. Automated synthesis of backbone protected peptides. Chem. Commun. 50, 8316-8319 (2014).

32. Kemp, D. \& Carey, R. I. Synthesis of a 39-peptide and a 25 -peptide by thiol capture ligations: observation of a 40 -fold rate acceleration of the intramolecular $\mathrm{O}, \mathrm{N}$-acyl-transfer reaction between peptide fragments bearing only cysteine protective groups. J. Org. Chem. 58, 2216-2222 (1993).

33. Bi, S., Liu, P., Ling, B., Yuan, X. \& Jiang, Y. Mechanism of N-to-S acyl transfer of N-(2-hydroxybenzyl) cysteine derivatives and origin of phenol acceleration effect. Chin. Chem. Lett. 29, 1264-1268 (2018).

34. Schroll, A. L., Hondal, R. J. \& Flemer, S. Jr. 2, 2'-Dithiobis (5-nitropyridine) (DTNP) as an effective and gentle deprotectant for common cysteine protecting groups. J. Pep Sci. 18, 1-9 (2012).

35. Burlina, F., Papageorgiou, G., Morris, C., White, P. D. \& Offer, J. In situ thioester formation for protein ligation using $\alpha$-methylcysteine. Chem. Sci. 5, 766-770 (2014).

36. El Oualid, F. et al. Chemical synthesis of ubiquitin, ubiquitin-based probes, and diubiquitin. Angew. Chem. Int. Ed. Engl. 49, 10149-10153 (2010).

37. Castillo-Pazos, D. J. \& Macmillan, D. Investigation of cysteine as an activator of side-chain $\mathrm{N} \rightarrow \mathrm{S}$ acyl transfer and tail-to-side-chain cyclization. Synlett 28, 1923-1928 (2017).

38. Tokunaga, F. et al. Involvement of linear polyubiquitylation of NEMO in NFкB activation. Nat. Cell Biol. 11, 123-132 (2009).

39. Ashida, H. et al. A bacterial E3 ubiquitin ligase IpaH9.8 targets NEMO/IKK $\gamma$ to dampen the host NF-kB-mediated inflammatory response. Nat. Cell Biol. 12, 66-73 (2010)

40. Rahighi, S. et al. Specific recognition of linear ubiquitin chains by NEMO is important for NF-kB activation. Cell 136, 1098-1109 (2009).

41. Hejjaoui, M., Haj-Yahya, M., Kumar, K., Brik, A. \& Lashuel, H. A. Towards elucidation of the role of ubiquitination in the pathogenesis of Parkinson's disease with semisynthetic ubiquitinated a-synuclein. Angew. Chem. Int. Ed. Eng. 50, 405-409 (2011).

42. Meier, F. et al. Semisynthetic, site-specific ubiquitin modification of $\alpha$ synuclein reveals differential effects on aggregation. J. Am. Chem. Soc. 134, 5468-5471 (2012).

43. Cardona, V. M. F., Hartley, O. \& Botti, P. Synthesis of cyclic peptides from unprotected precursors using removable Na-(1-(4-methoxyphenyl)-2mercaptoethyl) auxiliary. J. Pep Res 61, 152-157 (2003)

44. Raz, R. et al. HF-free Boc synthesis of peptide thioesters for ligation and cyclization. Angew. Chem. Int. Ed. Engl. 55, 13174-13179 (2016).

45. Hrdinka, M. \& Gyrd-Hansen, M. The Met1-linked ubiquitin machinery: emerging themes of (de) regulation. Mol. Cell 68, 265-280 (2017).

46. Hauenstein, A. V., Xu, G., Kabaleeswarran, V. \& Wu, H. Evidence for M1linked polyubiquitin-mediated conformational change in NEMO. J. Mol. Biol. 429, 3793-3800 (2017)

47. Ackrill, T., Anderson, D. W. \& Macmillan, D. Towards biomolecular assembly employing extended native chemical ligation in combination with thioester synthesis using an $\mathrm{N} \rightarrow \mathrm{S}$ acyl shift. Pep Sci. 94, 495-503 (2010).
48. Martin, S. R. \& Schilstra, M. J. Circular dichroism and its application to the study of biomolecules. Meth Cell Biol. 84, 263-293 (2008).

49. Sreerama, N. \& Woody, R. W. Estimation of protein secondary structure from circular dichroism spectra: comparison of CONTIN, SELCON, and CDSSTR methods with an expanded reference set. Anal. Biochem. 287, 252-260 (2000).

\section{Acknowledgements}

This work was supported by a Biotechnology and Biological Sciences Research Council Project grant (BB/R003750/1) to B.S. and the Francis Crick Institute which receives its core funding from cancer research UK (FC001999), the UK Medical Research Council (FC001999) and the Wellcome Trust (FC001999).

\section{Author contributions}

F.B., B.S., and J.O. conceived and designed the work. FB conducted ligations. A-B.M.A-A. synthesised NEMO and model peptides used in this study. R.R. synthesised ubiquitin. I.P. conducted the ubiquitylation assay. G.P. synthesised the auxiliary and optimised its synthesis. J.L. monitored ubiquitlylation of NEMO by gel. R.A. carried out LCMS analysis of products. S.R.M. performed biolayer interferometer. S.K. performed CD studies. F.B., B.S., and J.O. wrote the manuscript.

\section{Additional information}

Supplementary information accompanies this paper at https://doi.org/10.1038/s42004 019-0211-7.

Competing interests: The authors declare no competing interests.

Reprints and permission information is available online at http://npg.nature.com/ reprintsandpermissions/

Publisher's note Springer Nature remains neutral with regard to jurisdictional claims in published maps and institutional affiliations.

pen Access This article is licensed under a Creative Commons Attribution 4.0 International License, which permits use, sharing, adaptation, distribution and reproduction in any medium or format, as long as you give appropriate credit to the original author(s) and the source, provide a link to the Creative Commons license, and indicate if changes were made. The images or other third party material in this article are included in the article's Creative Commons license, unless indicated otherwise in a credit line to the material. If material is not included in the article's Creative Commons license and your intended use is not permitted by statutory regulation or exceeds the permitted use, you will need to obtain permission directly from the copyright holder. To view a copy of this license, visit http://creativecommons.org/ licenses/by/4.0/.

(C) Crown 2019 